\title{
Properties of Pinus Modified with Silicon-Titanium Binary Oxides
}

\author{
Xiaoling Liu, ${ }^{a}$ Songwu Chen, ${ }^{\mathrm{a}, *}$ and Yunlin $\mathrm{Fu}{ }^{\mathrm{b}, *}$ \\ Modification of Pinus yunnanensis using $\mathrm{SiO}_{2}-\mathrm{TiO}_{2}$ was carried out via the \\ sol-gel method. The aim was to improve the hydrophobicity, aging \\ resistance, and photocatalysis of the wood surface via the formation of \\ new chemical bonds with penetrated $\mathrm{SiO}_{2}$ and $\mathrm{TiO}_{2}$. The air-dried $P$. \\ yunnanensis wood underwent penetration, gelation, aging, and drying. \\ The wood was exposed to high temperatures for modification, and its \\ microstructure, composition, photodegradability, resistance to aging, \\ dimensional stability, and hydrophobicity were then determined. The \\ results indicated that during modification, $\mathrm{SiO}_{2}-\mathrm{TiO}_{2}$ gel was generated in \\ the wood, and the content of the gel increased as penetration time was \\ extended. No structural change in the wood was observed. Meanwhile, \\ chemical bonds were formed among $\mathrm{SiO}_{2}, \mathrm{TiO}_{2}$, and wood. The contact \\ angle of the modified wood increased noticeably relative to that of \\ unmodified wood. This increase indicated a noticeable increase in the \\ hydrophobicity of the wood surface. The modified wood exhibited high \\ photocatalytic degradation; however, its durability was not evident. The \\ water absorption and thickness swelling of the modified wood markedly \\ increased. After ultraviolet-aging resistance testing, the color change in \\ the surface of the modified wood was noticeably less than that of the \\ unmodified wood.
}

Keywords: Pinus yunnanensis wood; Sol-gel method; Silicon dioxide; Titanium dioxide; Photocatalysis

Contact information: a: Guangxi Forestry Research Institute, Nanning 530002, China; $b$ : Forestry College of Guangxi University, Nanning 530005, China; *Corresponding author: Fylin@126.com

\section{INTRODUCTION}

With the development and utilization of natural resources and the emergence of novel materials, functional wood has received increasing attention. Modification technologies have recently been used to improve wood properties such as magnetism (Jin et al. 2015; Pan et al. 2015; Guo 2017; Lou et al. 2017; Muff et al. 2018), photocatalysis (Mo et al. 2012; Jin et al. 2015; Li et al. 2015; Lin et al. 2015; Rao et al. 2016; Dong et al. 2017; Chang et al. 2018), and aging resistance (Guo et al. 2016; Li et al. 2018), among others (Liu et al. 2013; Guo et al. 2015; Zhang et al. 2015; Huang et al. 2016). To summarize, there are many methods of inorganic modification of wood, but there are some drawbacks. Most of the inorganic substances belong to the classification of refractory material. Such treatments are done with the help of external pressure, which is needed so that the sol will enter the wood cell cavity or cell walls. The resulting effects are mainly due to physical filling, not chemical changes. However, the inorganic modified wood prepared in previous studies still has not very well met the needs for surface hydrophobicity, aging resistance, and photocatalysis improvement effects, especially hydrophobicity. However, most wood modification technologies are complex and costly, 
impeding their broad applications. Therefore, simple, feasible, efficient, and low-cost wood modification technologies need to be developed.

Wood modified with inorganic substances has the potential not only to ensure structural integrity; it also can be environment-friendly, less expensive, and result in significant improvements in the physical, mechanical, and surface properties of wood. Wood that has been modified using inorganic substances has recently drawn considerable attention, particularly for the functional improvement of wood. Common methods of wood modification using inorganic substances include the sol-gel method, the penetration method, in situ synthesis, and the hydrothermal method. The reaction precursor for the solgel method is generally a metal alcohol salt, but also it may consist of some salts, hydroxides, esters, etc., with water as an initiator or solvent. The reaction process generally involves the precursor being added to the solvent, stirring, and forming a uniform solution, hydrolysis reaction at a certain reaction temperature, and the formation of sol. The sol is generated by the reaction, and in the course of drying, condensation makes the structure change, such that the gel forms a network structure. Because the reaction working temperature required by sol-gel method is relatively low and the operation is not complicated. The conditions are favorable for retaining the characteristics of wood itself. As a result of the treatment, the wood is endowed with new functions, which has been widely used in the research of ceramics, glass, wood, biological materials, and many functional materials.

Saka et al. (1992) produced wood/inorganic composites using the sol-gel method and found that the composites exhibited dimensional stability and flame retardancy. Miyafuji et al. (1998) produced $\mathrm{SiO}_{2}-\mathrm{P}_{2} \mathrm{O}_{5}-\mathrm{B}_{2} \mathrm{O}_{3}$ wood/inorganic composites via the solgel method and observed an increase in leaching resistance in the composites. Ogiso and Saka (1994) produced wood/inorganic composites loaded with $\mathrm{SiO}_{2}$ gel via the sol-gel method and demonstrated that the heat resistance and dimensional stability of wood were improved significantly. Sun et al. (1998) prepared wood/SiO $\mathrm{Sin}_{2}$ nanocomposites by pretreating wood with conventional or coupling agents and found that the properties of wood $/ \mathrm{SiO}_{2}$ nanocomposites were improved. Liao et al. (2001) prepared wood $/ \mathrm{SiO}_{2}$ composites and wood/methyl methacrylate (PMMA)/SiO 2 composites using ethyl silicate and PMMA as precursors and modifiers, respectively. Wu and Zhang (2011) used the solgel method to prepare nano- $\mathrm{TiO}_{2} /$ wood composites with tetrabutyl titanate as the titanium source. Anatase crystalline $\mathrm{TiO}_{2}$ composites improve heat resistance and flame retardancy. $\mathrm{SiO}_{2}$ and $\mathrm{TiO}_{2}$ are commonly used as inorganic substances in wood modification and have produced desirable effects. However, $\mathrm{SiO}_{2}$ or $\mathrm{TiO}_{2}$ have merely been shown to improve the surface of wood (Wang et al. 2004; Qiu and Li 2005; Mo et al. 2009; Jiang et al. 2010; Ye and $\mathrm{Li}$ 2012; Zhang et al. 2012) and have not been reported to endow wood with hydrophobicity and photocatalytic properties. In particular, this problem was observed in Pinus yunnanensis, which is widely planted in Guangxi but used in a limited capacity due to its soft texture and poor hydrophobicity.

Titanium dioxide is a type of amphoteric oxide, which can have the form of a white solid or powder. It is generally available as either the anatase or rutile crystalline type. At room temperature, $\mathrm{TiO}_{2}$ in a thin layer form can be generated on a wood surface, and such treatment improves moisture absorption stability and aging resistance, etc. Studies show that $\mathrm{TiO}_{2}$ not only physically fills wood cell walls in the form of gel particles, but it also forms stable chemical bonds and combines with modified timber, which endows the prepared modified timber with good flame retardation and dimensional stability. The layered deposition method was adopted to generate $\mathrm{TiO}_{2}$ particles on the surface of 
cellulose fiber, so that the fiber has a self-cleaning surface and reinforcing body. This was used to prepare a polymer material formed by cellulose matrix composite material and polymer, with the goal of achieving good hydrophobicity and light stability. The wood/ $/ \mathrm{TiO}_{2}$ composite material with photocatalytic degradation was prepared by taking advantage of the photocatalytic action of $\mathrm{TiO}_{2}$, which could degrade organic matter. If the wood was first treated with silicate, then the prepared wood/ $/ \mathrm{SiO}_{2} / \mathrm{TiO}_{2}$ composite material not only could maintain the original characteristics of the wood, but also it could achieve the degradation of organic matter. In the work described in this paper, titanium dioxide was introduced into wood by sol-gel method, which improves the moisture absorption and aging resistance of wood, makes wood fiber have self-cleaning surface and reinforcing body, has good hydrophobicity and photocatalysis, and improves the surface properties of wood.

Although great progress has been made in the improvement of inorganic wood, there are still many shortcomings. First of all, when wood is modified by inorganic salts, most of the inorganic salts only play a physical filling role. Secondly, most of the inorganic wood to improve the whole wood needs to use external pressure to enter the wood cell cavity and cell wall. The cost of impregnation under pressure is high and the operation has a certain difficulty. Again, by means of the surface improvement of wood, the surface properties of wood (hydrophobicity, anti-aging, photocatalysis, etc.) can be greatly improved and the function can be increased. Through hydrolysis of ethyl n-silicate alone, the free hydroxyl group on the wood surface is replaced by a silicon dioxide film, which reduces the moisture absorption effect of wood. However, the generated silicon dioxide film contains hydroxyl group itself, which is hygroscopic and cannot achieve the expected hydrophobicity effect. Existing studies have basically improved wood surface through $\mathrm{SiO}_{2}$ or $\mathrm{TiO}_{2}$ alone, which cannot make wood have both hydrophobicity and photocatalytic ability. Therefore, this study proposes to improve $P$. yunnanensis using the sol-gel method. $\mathrm{SiO}_{2}$ and $\mathrm{TiO}_{2}$ were simultaneously loaded, forming a binary sol inside the wood. The microstructure, composition, surface hydrophobicity, durability, and photocatalytic properties of the modified wood were evaluated. Wood surface by simultaneously load $\mathrm{SiO}_{2}, \mathrm{TiO}_{2}$ binary oxide film modified, using the sol-gel method modifies the wood surface by means of generation of a dual sol. Through the high temperature effect the dual oxide film undergoes sintering, by which the non-crystalline structure into a crystalline structure, strengthen the wood's hydrophobicity, aging resistance, and light catalytic role.

\section{EXPERIMENTAL}

\section{Materials}

Pinus yunnanensis was collected from the Yachang Forests in Baise City, Guangxi Province, China. After the sample was collected, the sample was first dried to the moisture content of about $15 \%$. After planing and 120 mesh sanding, the wood was cut into specimens measuring $95 \mathrm{~mm} \times 65 \mathrm{~mm} \times 5 \mathrm{~mm}$ and $20 \mathrm{~mm} \times 20 \mathrm{~mm} \times 20 \mathrm{~mm}$. The sample $95 \mathrm{~mm} \times 65 \mathrm{~mm} \times 5 \mathrm{~mm}$ was used for the aging resistance test (tangential section was the test surface), and $20 \mathrm{~mm} \times 20 \mathrm{~mm} \times 20 \mathrm{~mm}$ was used for dimensional stability, microscopic performance, photocatalysis and other performance test. Ethyl orthosilicate, tetrabutyl titanate, ethanol, nitric acid, and the azo dye AO7 were purchased from Songyuan Chemical and Glass Instrument Co., Ltd. in Nanning City, China. 


\section{Treatment of wood}

The prepared silicon and titanium unit sol were mixed proportionally via the solgel method $(\mathrm{n} 1(\mathrm{Si}): \mathrm{n} 2(\mathrm{Ti})=1: 2)$, and the wood was immersed (immersion time $=2,4,6$, and $8 \mathrm{~h}$ ) to allow penetration. After aging for $5 \mathrm{~d}$ and air drying, the wood specimen was subjected to high-temperature treatment at $250{ }^{\circ} \mathrm{C}$ for $20 \mathrm{~min}$. Then, the wood surface was loaded with silicon-titanium dual oxide film.

\section{Methods}

Microscopic and morphological characterization of the wood surface

Changes in the wood structure were observed using a stereomicroscope (Discovery V20; Carl Zeiss Micro Imaging, Jena, Germany). The morphology of each section of the wood was analyzed using an S-3400N scanning electron microscope (SEM, Hitachi Ltd., Tokyo, Japan); and the distribution of $\mathrm{SiO}_{2}$ and $\mathrm{TiO}_{2}$ in the wood was observed using a PV8200 energy-dispersive spectroscope (EDAX; Hitachi Ltd., Tokyo, Japan). The chemical structures of $\mathrm{SiO}_{2}$ and $\mathrm{TiO}_{2}$ in wood and their interaction with wood components were analyzed using a Nicolet 6700 Fourier-transform infrared spectroscope (FTIR, Nicolet 6700; Thermo Fisher, Waltham, MA, USA) under the following conditions: optical resolution of $4 \mathrm{~cm}^{-1}$; wavenumber accuracy of $0.01 \mathrm{~cm}^{-1}$; scanning range of 4000 to 400 $\mathrm{cm}^{-1}$; and number of scans, 32. The crystallization of $\mathrm{SiO}_{2}$ and $\mathrm{TiO}_{2}$ in the wood was analyzed by X-ray diffraction (XRD) (Rigaku SmartLab, Tokyo, Japan), and the scanning range was $10^{\circ}$ to $70^{\circ}$.

\section{Hydrophobicity of wood samples}

The contact angles of distilled water on samples before and after aging were determined using a contact angle instrument (Krüss DSA100S; Krüss GmbH, Hamburg, Germany). The droplet volume was set to $2 \mu \mathrm{L}$, and the contact angle of the $30^{\text {th }}$ droplet was determined. Measurements were conducted on both tangential and radial sections. Three measurements were performed on each surface, and their means were assigned as the contact angles of the samples.

\section{Photocatalysis of wood samples}

The degradation of the azo dye AO7 (target pollutant) by the modified wood samples was determined. The photocatalytic activity was determined using two methods. One method involved evenly coating the surfaces of the samples with the AO7 solution at $100 \mathrm{mg} / \mathrm{L}$. The samples were left to sit horizontally to allow complete absorption of the AO7 solution, and then the specimens were exposed to ultraviolet (UV) light. The chromatic aberration of the samples was determined hourly; subsequently, the photocatalytic effect of the modified material on the azo dye AO7 was evaluated. The other method involved soaking the wood samples in the AO7 solution at $40 \mathrm{mg} / \mathrm{L}$ and then placing the solution under UV light. The absorbance of the solution at $\lambda=484 \mathrm{~nm}$ was measured using a UV spectrophotometer (Ultrospec 2100 pro; Biochrom Ltd., Cambridge, England), and the concentration was calculated based on the standard curve. Changes in AO7 concentration after photocatalysis were determined.

\section{Aging resistance of the wood samples}

Aging of the wood samples under outdoor light was simulated using a spray-type QUV/SPRAY UV aging instrument (Q-Lab Corporation, Shanghai, China); the lamp type was UVA-340, and the light intensity was $0.89 \mathrm{w} / \mathrm{m}^{2}$. To characterize the aging resistance 
of the samples, the surface chromaticity coordinate values $L^{*}$ (lightness), $a^{*}$ (red/green), and $b^{*}$ (yellow/blue) of each sample were measured using an ADCI-60-C automatic colorimeter (Chentaike Instrument Technology Co., Ltd., Beijing, China). The difference in the total color difference $(\Delta E)$ of the sample surface before and after aging was calculated according to Eq. 1,

$$
\Delta E=\left(\Delta L^{2}+\Delta a^{2}+\Delta b^{2}\right)^{1 / 2}
$$

where $\triangle L^{*}, \triangle a^{*}$, and $\triangle b^{*}$ represent the changes in $L, a$, and $b$, respectively.

\section{Dimensional stability of wood samples}

The modified wood samples were dried in an oven. The oven-dried wood samples were stored in the dryer until use. After cooling down, the samples were placed on a paper board with small holes on it, and the bottom of the dryer was filled with an appropriate amount of distilled water. The weight and dimensions of the wood samples were determined every $6 \mathrm{~h}$. The dimensional stability of the wood samples was indicated by their water absorption and thickness swelling, which were calculated according to Eqs. 2 and 3,

$$
\triangle m=\frac{m_{1}-m_{0}}{m_{0}} \times 100 \%
$$

where $\triangle m$ was the water absorption rate $(\%), m_{0}$ was the oven-dry weight $(\mathrm{g})$ of the samples, and $m_{1}$ was the weight $(\mathrm{g})$ of the samples at the time of measurement. Equation 3 was as follows,

$$
\triangle L=\frac{L_{1}-L_{0}}{L_{0}} \times 100 \%
$$

where $\triangle L$ was the thickness swelling (\%) of the wood samples, $L_{0}$ was the dimension (mm) of the oven-dried samples, and $L_{1}$ was the dimension $(\mathrm{mm})$ of the samples at the time of measurement.

\section{RESULTS AND DISCUSSION}

\section{Microscopic and Structural Morphology of the Wood Surface}

Microscopic image analysis

The transverse, tangential, and radial sections of the modified wood are presented in Fig. 1.
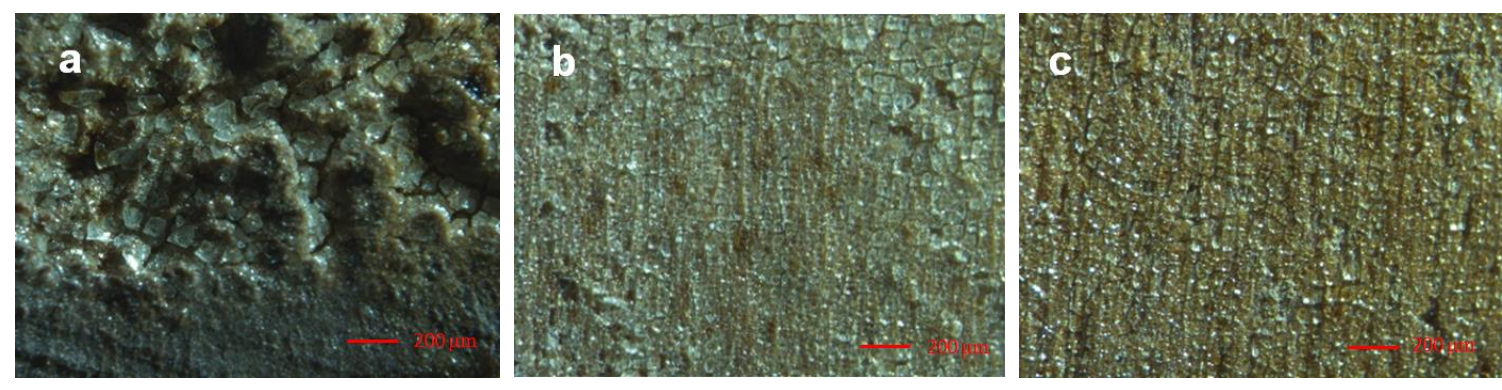

Fig. 1. Scanning electron microscopy images showing the (a) transverse, (b) tangential, and (c) radial sections of the modified wood 
Noticeable alterations in structures were apparent in the modified wood. As a softwood, $P$. yunnanensis features regularly arranged tracheids, soft texture, and evident differences between earlywood and latewood. The tracheids in the modified wood were evenly filled with gel. The SEM images of the wood before and after modification are shown in Fig. 2. In the modified wood, solid precipitation along the cell wall and cell lumen was clearly observed, which likely consisted of silicon-titanium oxides formed in situ by using the sol-gel method. Blocks of $\mathrm{SiO}_{2}$ and $\mathrm{TiO}_{2}$ filled in the vessels or covered the surface of the wood and were attached to the cell wall via chemical bonds and/or physical absorption, a basis for improving the hydrophobicity of the wood.
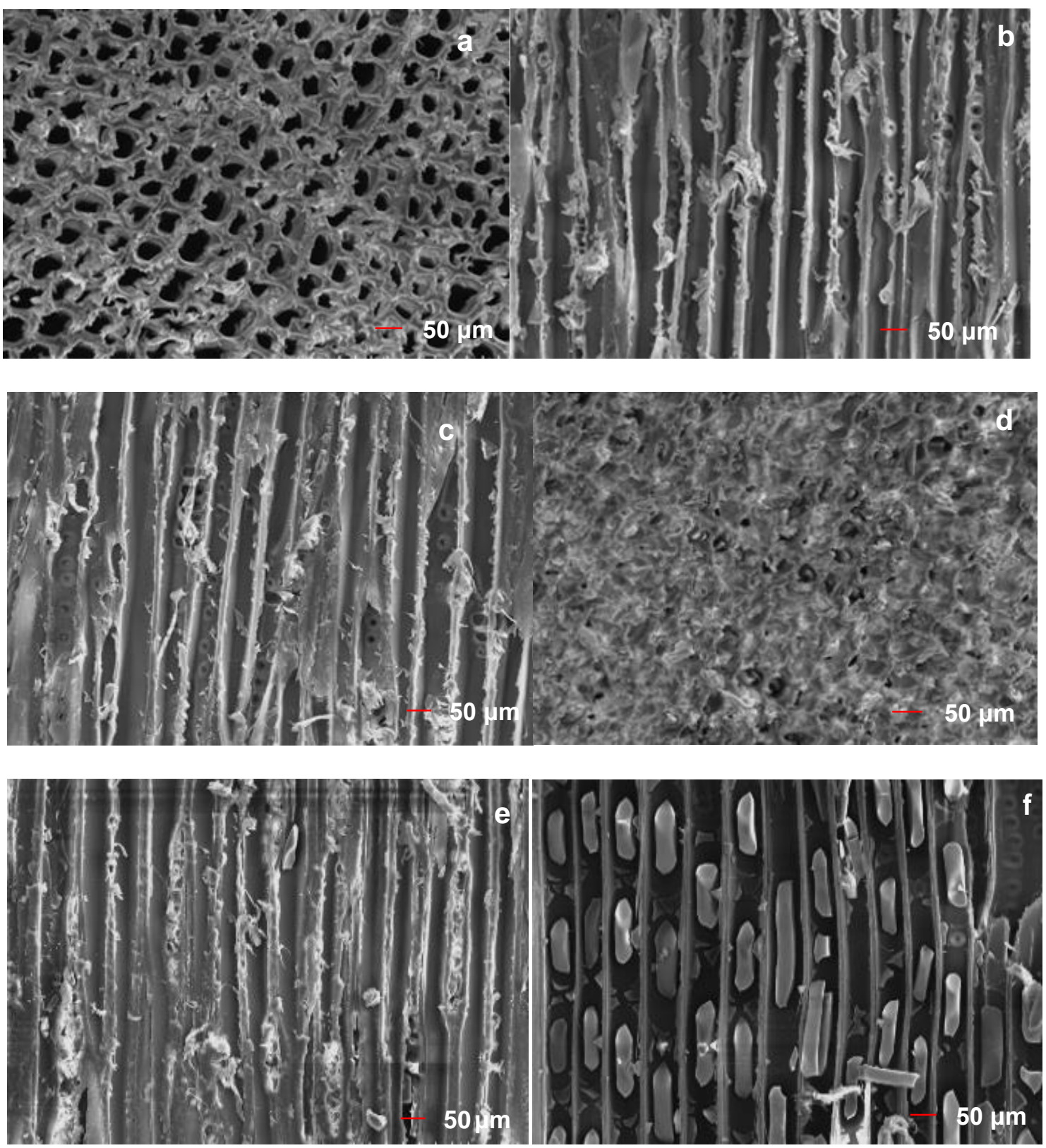

Fig. 2. Scanning electron microscopy images showing the (a) transverse, (b) tangential, and (c) radial sections of the unmodified wood and the (d) transverse, (e) tangential, and (f) radial sections of the modified wood 
Compositional analysis of the modified wood with different penetration times

Figure 3 presents plots showing the Si and Ti contents of the wood samples treated with different penetration times, as revealed by EDAX analysis. Compared with those in the unmodified samples, the Si and Ti contents in the modified samples were increased noticeably, and both the $\mathrm{Si}$ and $\mathrm{Ti}$ contents increased with penetration time. When the penetration time was set to $8 \mathrm{~h}$, the maximum Si and Ti contents were achieved - that is, $0.48 \%$, and $1.54 \%$ respectively.
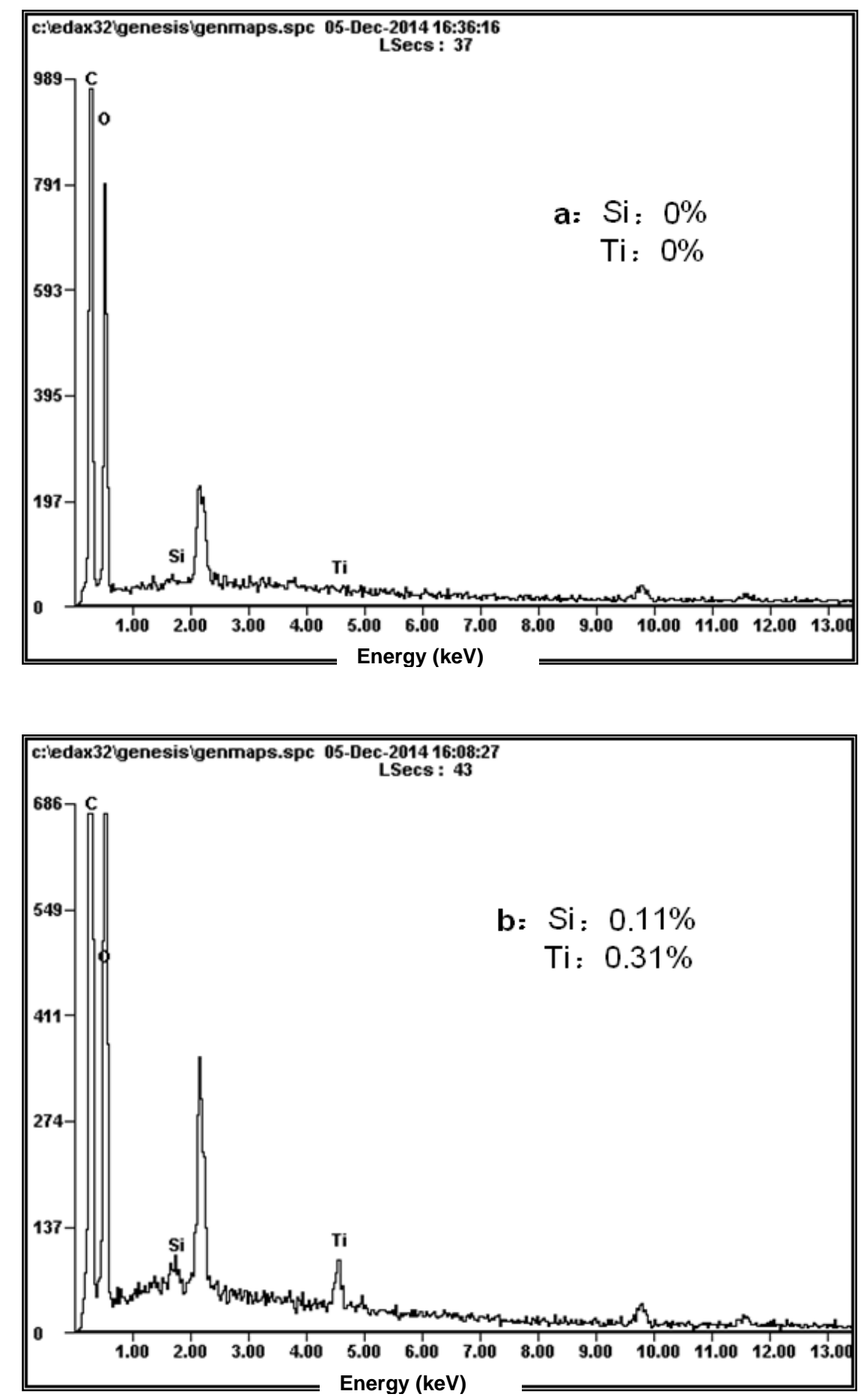

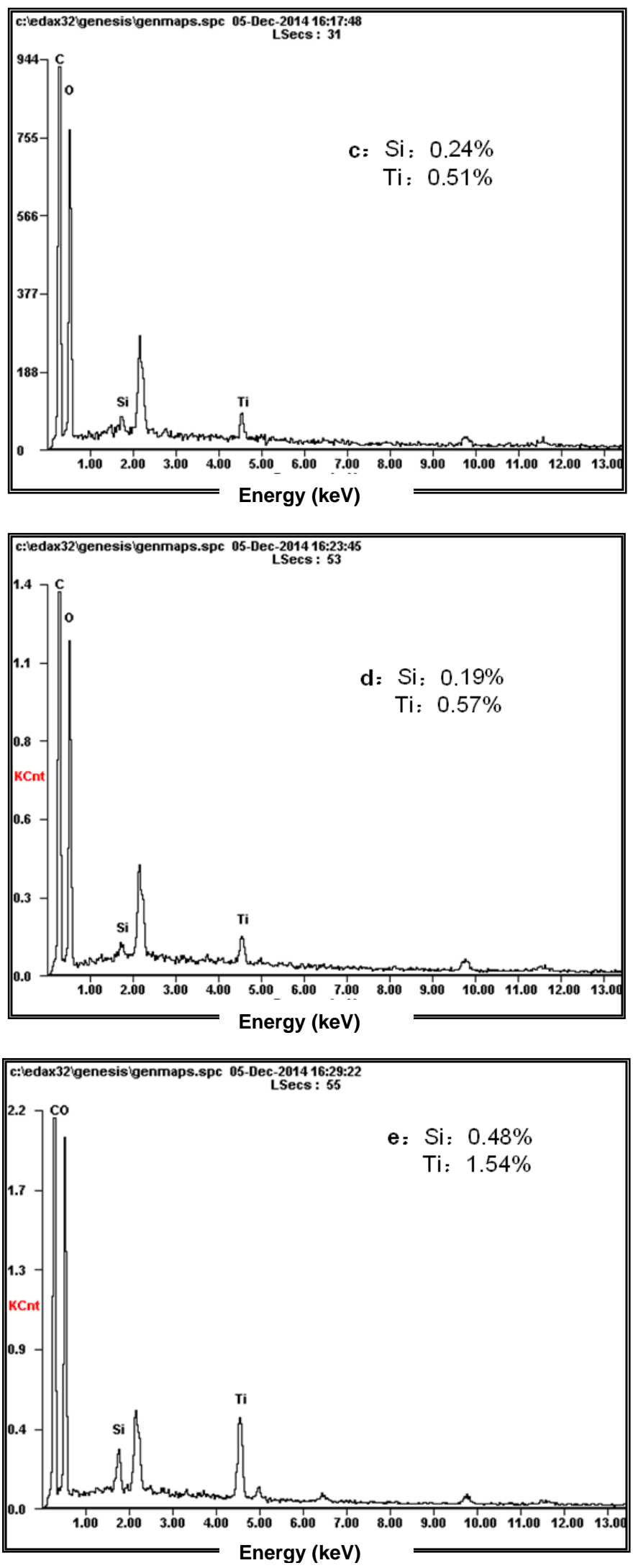

Fig. 3. Energy dispersive $x$-ray analysis diagram of the modified and unmodified wood; (a) unmodified wood, (b) wood with $2 \mathrm{~h}$ penetration, (c) wood with $4 \mathrm{~h}$ penetration, (d) wood with $6 \mathrm{~h}$ penetration, and $(\mathrm{e})$ wood with $8 \mathrm{~h}$ penetration 
The FTIR spectra of the unmodified and modified wood with different penetration times are shown in Fig. 4. The characteristic peaks of major wood components-lignin $\left(1730 \mathrm{~cm}^{-1}\right)$, cellulose $\left(1630 \mathrm{~cm}^{-1}\right)$, and hemicellulose $\left(1025 \mathrm{~cm}^{-1}\right)$ - showed no changes before and after modification, suggesting that the modification did not alter the wood's chemical structure. Compared with the unmodified wood, the modified wood showed several new peaks. The peaks at 1025 and $789 \mathrm{~cm}^{-1}$ were attributed to the stretching vibration of Ti-O-Si and absorption vibration of $\mathrm{Ti}-\mathrm{O}-\mathrm{C}$, this is consistent with the research of Zhong et al. (2002), suggesting that after modification, $\mathrm{TiO}_{2}$ successfully entered the inside of wood and chemically bonded with the wood.

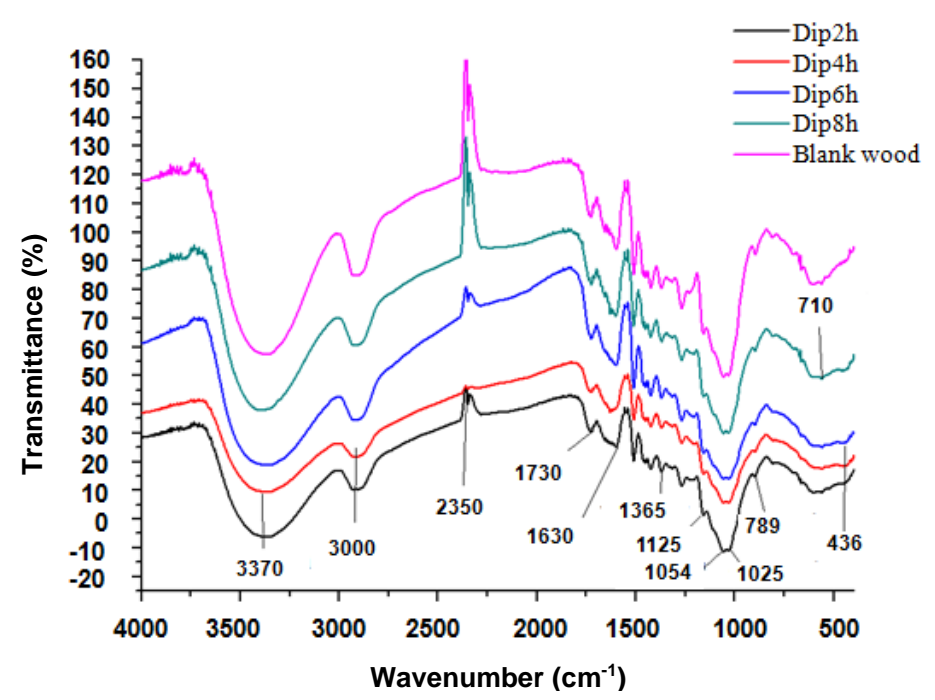

Fig. 4. Fourier-transform infrared spectra of the unmodified and modified wood with different penetration times

The samples were further analyzed by XRD (Fig. 5).

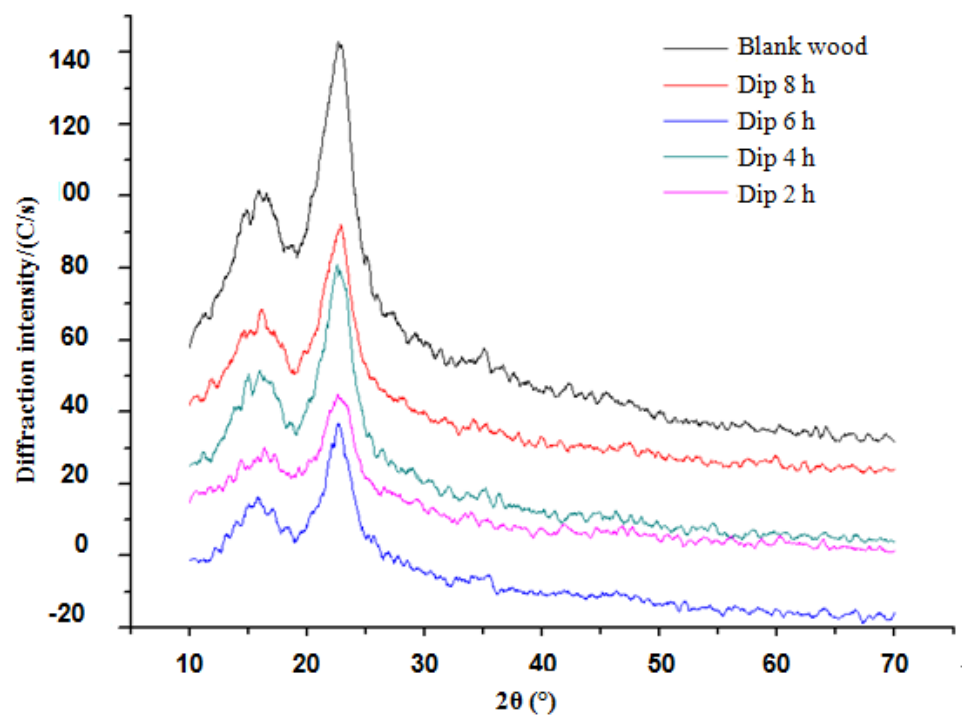

Fig. 5. XRD diagram of the modified and unmodified wood 
The position of the diffraction peak $2 \theta=23.6^{\circ}$ was not changed after modification, suggesting that the unit cell parameters of the wood remained the same. This finding further revealed that modification did not alter the wood chemical structure. Meanwhile, the intensity of the diffraction peak changed noticeably, suggesting large amounts of $\mathrm{SiO}_{2}$ and $\mathrm{TiO}_{2}$ were formed using the sol-gel method. But with relatively unmodified wood, the intensity of the diffraction peak differed from the modified wood. Because $\mathrm{SiO}_{2}$ has lower crystallinity, for specimens after high temperature processing, a small diffraction peak of the modified wood was apparent at about $25^{\circ}$; this corresponded to the $\mathrm{TiO}_{2}$ anatase form, which is consistent with the research of Wu et al. (2011). However, with the increase of the impregnation time, the content of $\mathrm{SiO}_{2}$ and $\mathrm{TiO}_{2}$ generated on the surface and inside of the wood increased, the relative content of the wood decreased, and the diffraction peak strength decreased.

\section{Analysis of the hydrophobicity of the wood surface}

The major chemical components of wood include cellulose, hemicellulose, and lignin, all of which are rich in hydrophilic groups that impart relatively high hydrophilicity to wood. The contact angles of the modified and unmodified wood samples are presented in Fig. 6, and the measurements are listed in Table 1. The contact angles of the modified wood were larger than those of the unmodified wood samples. The contact angles of the tangential and radial sections were almost similar and larger than those of the cross-section. The modification increased the contact angles from $61.3^{\circ}$ to $121.1^{\circ}$, suggesting a noticeably increased hydrophobicity. This effect was attributable to the wood surface being coated with $\mathrm{SiO}_{2}-\mathrm{TiO}_{2}$ or bonds with the hydroxyl groups on the wood surface, which greatly reduced the exposure of hydrophilic groups on the wood surface, limiting moisture absorption. The modification also led to the formation of a hydrophobic film on the wood surface, further enhancing its hydrophilicity. In addition, the nanoscale titanium dioxide that formed on the wood surface during modification noticeably increased the intrinsic roughness of the wood, which further increased the hydrophilicity of the wood. The contact angle of the modified wood before and after aging changed noticeably, with the maximum difference reaching $62^{\circ}$. This result suggested the relatively low durability of the modified wood, which greatly depended on the intrinsic structure of the wood.

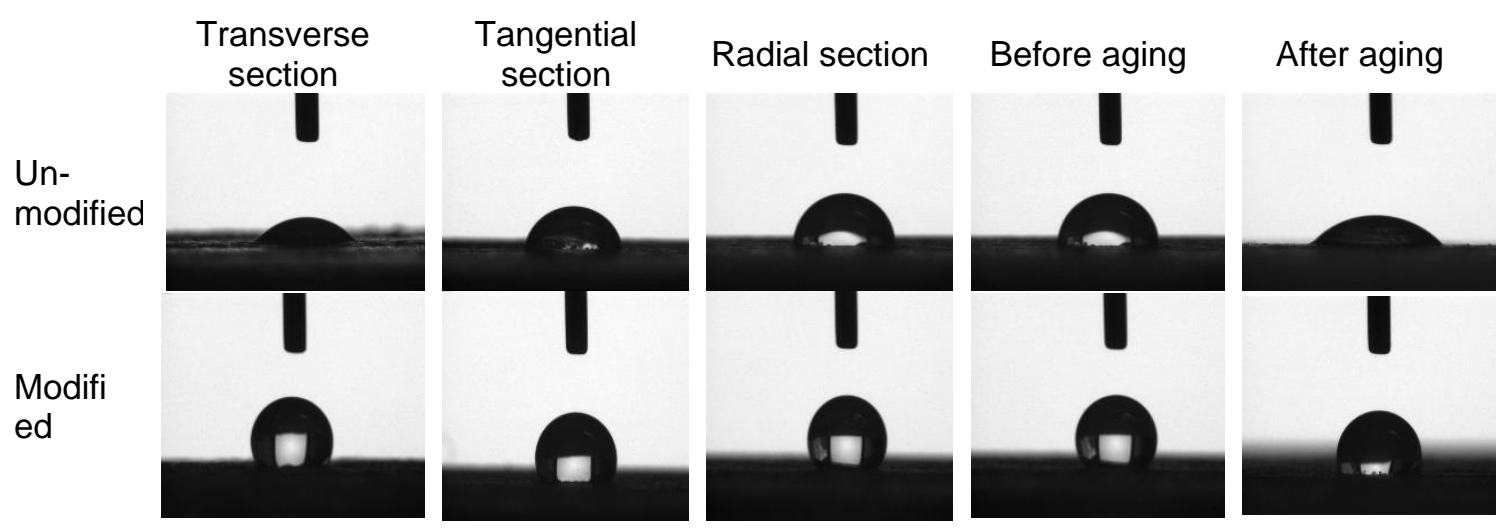

Fig. 6. Contact angles of the modified and unmodified Pinus yunnanensis wood samples 
Table 1. Contact Angles $\left({ }^{\circ}\right)$ of the Wood Samples

\begin{tabular}{|c|c|c|c|c|c|c|}
\hline Samples & Transverse & Tangential & Radial & Mean & After aging & Difference \\
\hline Unmodified & 22.3 & 78.5 & 83.2 & 61.3 & 28.9 & 32.4 \\
\hline $\begin{array}{c}2 \mathrm{~h} \\
\text { penetration }\end{array}$ & 113.7 & 118.3 & 119.2 & 117.1 & 84.4 & 32.7 \\
\hline $\begin{array}{c}4 \mathrm{~h} \\
\text { penetration }\end{array}$ & 110.1 & 121.0 & 120.1 & 117.1 & 84.6 & 32.5 \\
\hline $\begin{array}{c}6 \mathrm{~h} \\
\text { penetration }\end{array}$ & 120.6 & 124.1 & 118.6 & 121.1 & 59.2 & 62.0 \\
\hline $\begin{array}{c}8 \mathrm{~h} \\
\text { penetration }\end{array}$ & 115.5 & 119.8 & 119.0 & 118.1 & 96.4 & 21.7 \\
\hline
\end{tabular}

Photocatalytic properties of modified wood

Color changes in wood samples during photocatalysis are shown in Fig. 7. The lightness of the samples changed with an increase in penetration time and reached a peak at $6 \mathrm{~h}$. Compared with the modified wood, the unmodified wood showed a markedly smaller total color difference $\triangle E$; moreover, the $2 \mathrm{~h}$ penetration period exerted the strongest effect. The results suggested that the modified wood exhibited substantial changes in surface color during photocatalysis, which were much more noticeably than those of the unmodified wood. Previous studies have indicated that $\mathrm{TiO}_{2}$ showed noticeably higher photocatalytic activity when its particle size reached the nanoscale (Sun et al. 1995). Due to its strong photocatalytic degradation, the $\mathrm{TiO}_{2}$ formed in situ on the wood surface during modification facilitated the photocatalytic degradation of the azo dye on the wood surface.
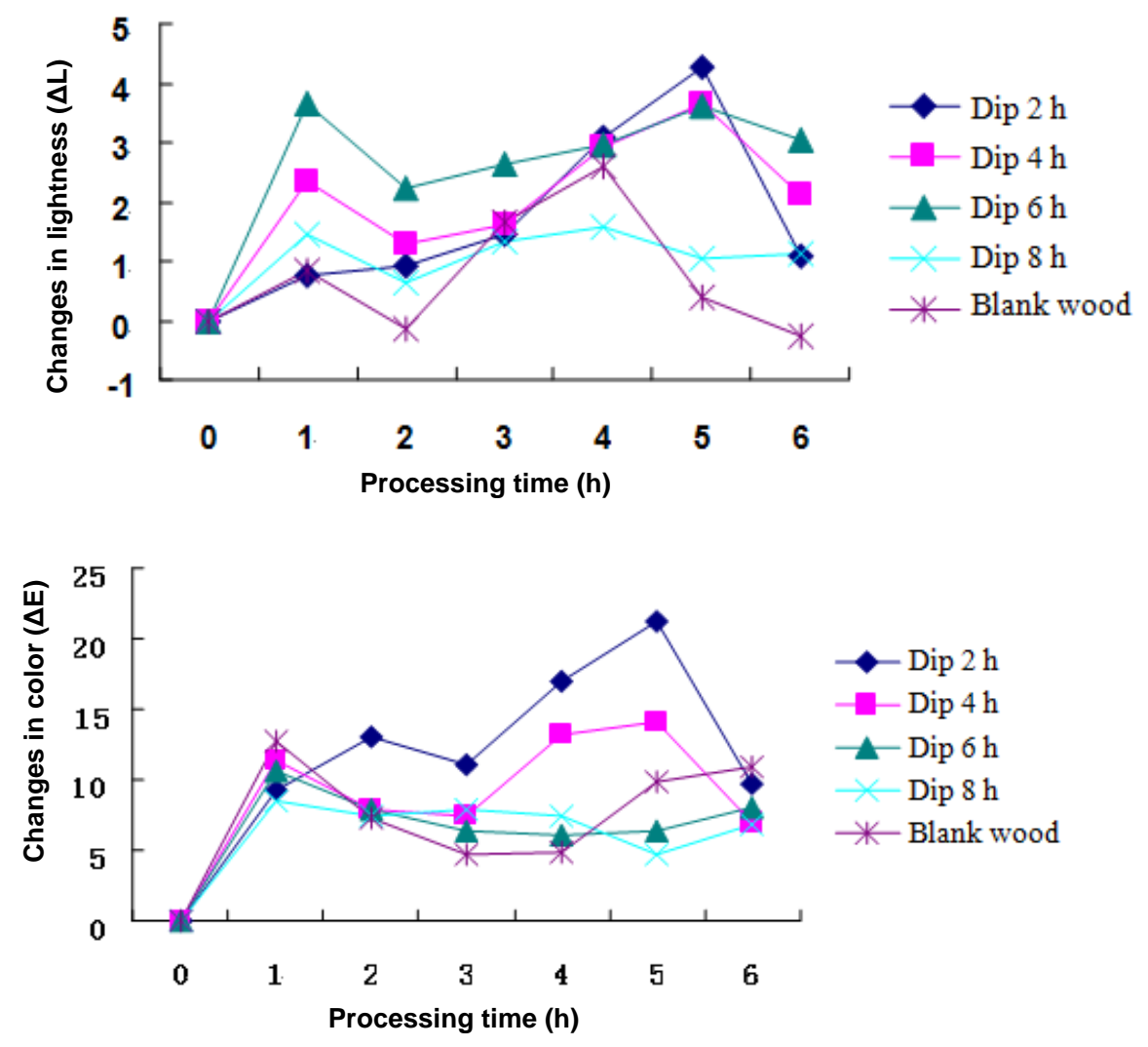

Fig. 7. Variations in $\Delta L$ and $\triangle E$ of wood during photocatalysis 


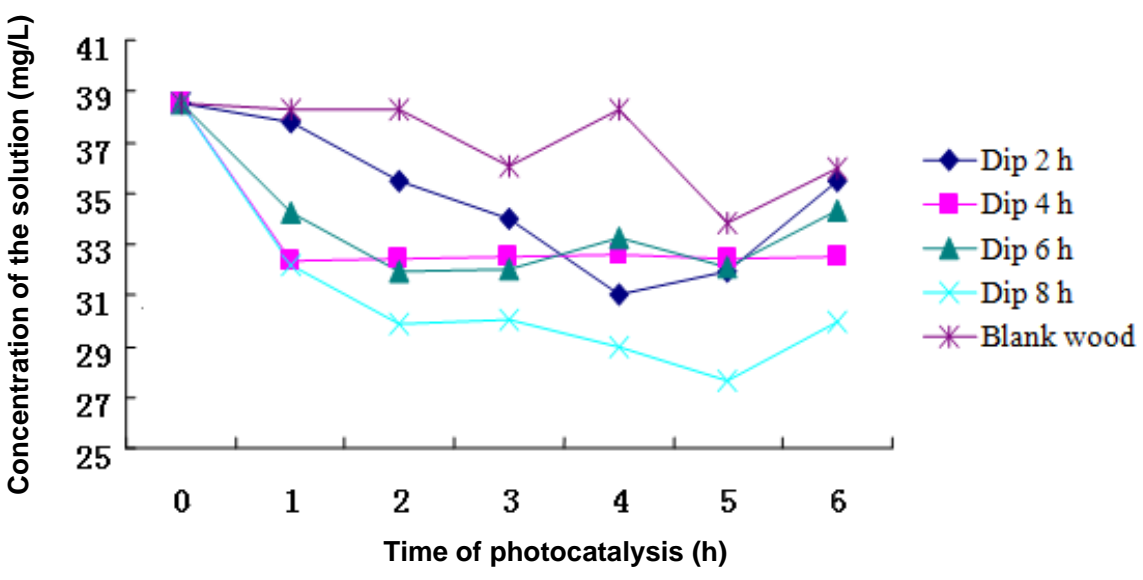

Fig. 8. Changes in concentration of the azo dye solution during photocatalysis

Figure 8 shows the changes in the concentration of the azo dye solution during photocatalysis. The concentration of the azo dye gradually decreased during photocatalysis, and the speed of degradation was higher for the wood samples modified with a longer penetration time. After photocatalysis for $6 \mathrm{~h}$, the modified wood with a penetration time of $8 \mathrm{~h}$ penetration decreased in AO7 concentration from $40 \mathrm{mg} / \mathrm{L}$ to 30 $\mathrm{mg} / \mathrm{L}$, whereas the unmodified wood decreased in AO7 concentration to only $36 \mathrm{mg} / \mathrm{L}$. This result suggested that the modified wood exhibited increased photocatalytic activity. The rate of degradation was relatively higher in the early stages of the photocatalytic reactions and then it decreased markedly at a certain stage of the reaction. This decrease was attributable the reduction in the reaction rate of the azo dye AO7 as its adsorption increased. At a low AO7 adsorption rate, the dissolved oxygen concentration on the catalyst surface was relatively high, and the electron transfer rate from excited $\mathrm{AO} 7$ to $\mathrm{TiO}_{2}$ increased as its adsorption increased. At a later stage of the reaction, the adsorption of AO7 was high, the diffusion rate of the dissolved oxygen toward the $\mathrm{TiO}_{2}$ surface decreased with decreasing oxygen concentration on the catalyst surface. The higher AO7 adsorption led to reduced oxygen concentration. Although the electron transferred from excited AO7 to $\mathrm{TiO}_{2}$ at a higher rate, the oxygen concentration on the $\mathrm{TiO}_{2}$ surface was not sufficiently high to accept the transferred electrons. Consequently, the rate of recombination between the positive carbon radical AO7+ and the electron increased, and the degradation of the azo dye AO7 was reduced. The modified wood with a penetration time of $8 \mathrm{~h}$ exhibited the highest adsorption, suggesting the high photocatalytic degradation of $\mathrm{TiO}_{2}$.

\section{Analysis of the aging resistance of the modified wood}

Figure 9 presents the change trends in color during photo-aging of different samples. The modified and unmodified wood samples showed considerably different change trends in lightness, which initially increased and then decreased with increasing penetration time. Compared with modified wood, the unmodified wood exhibited markedly higher $\triangle E$; the total color difference of the modified wood only varied slightly between different penetration times. Both $\triangle L$ and $\triangle E$ initially increased and then decreased with increasing penetration time, and the samples with a penetration time of $8 \mathrm{~h}$ varied the least during aging. After UV aging for $120 \mathrm{~h}$, the average total color difference of the modified wood was 5.6, whereas that of the unmodified wood was 23.7, suggesting a 4-fold increase 
in the aging resistance of wood resulting from the modification. This result was due to the formation of $\mathrm{a} \mathrm{SiO}_{2}-\mathrm{TiO}_{2}$ dual oxide film on the wood surface during modification, which absorbed UV light and noticeably increased the aging resistance of the modified wood.
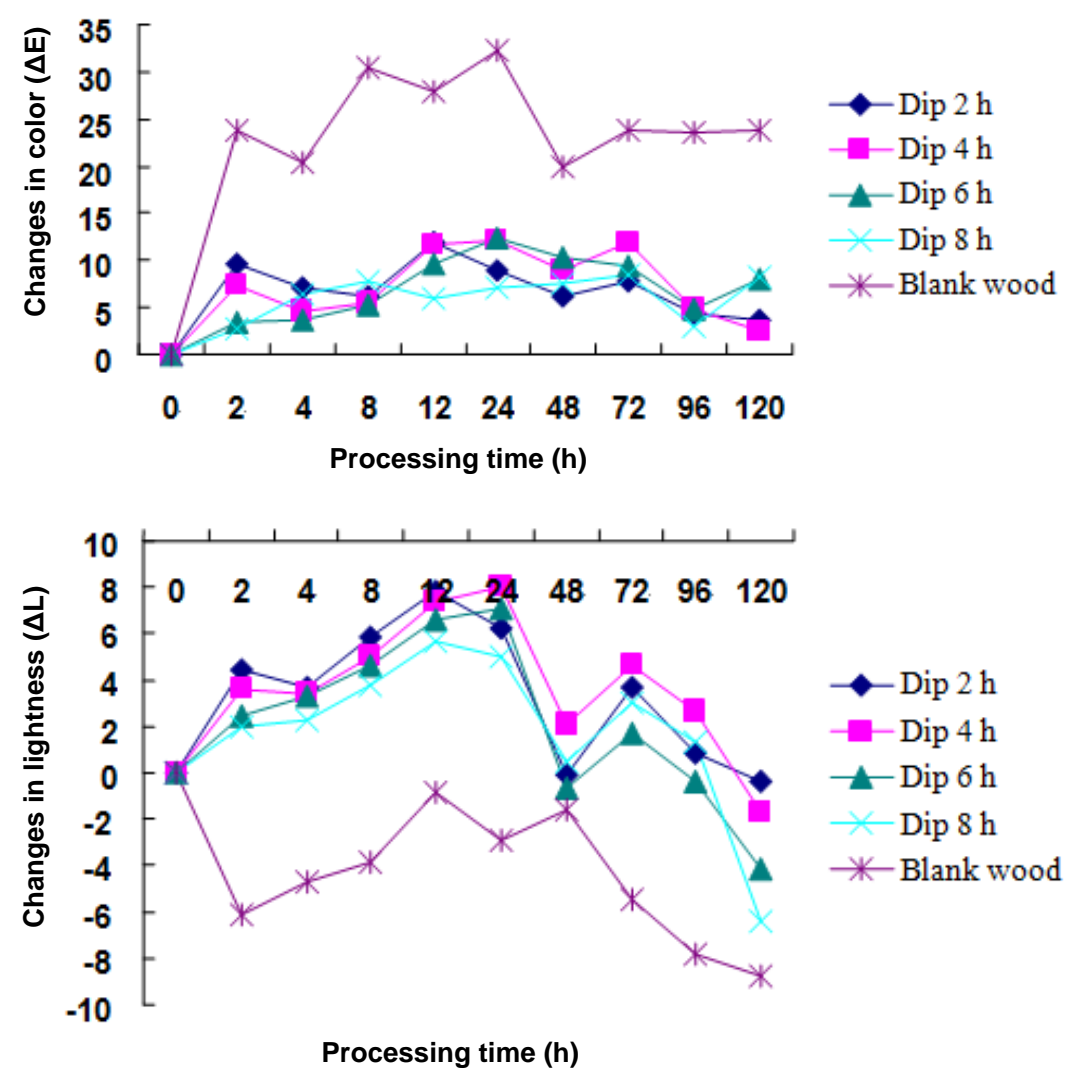

Fig. 9. Changes in $\triangle L$ and $\triangle E$ of the wood during aging

Effects of penetration time on the dimensional stability and water absorption of the wood

The water absorption amounts of the wood with different penetration times at different water absorption times are shown in Fig. 10.

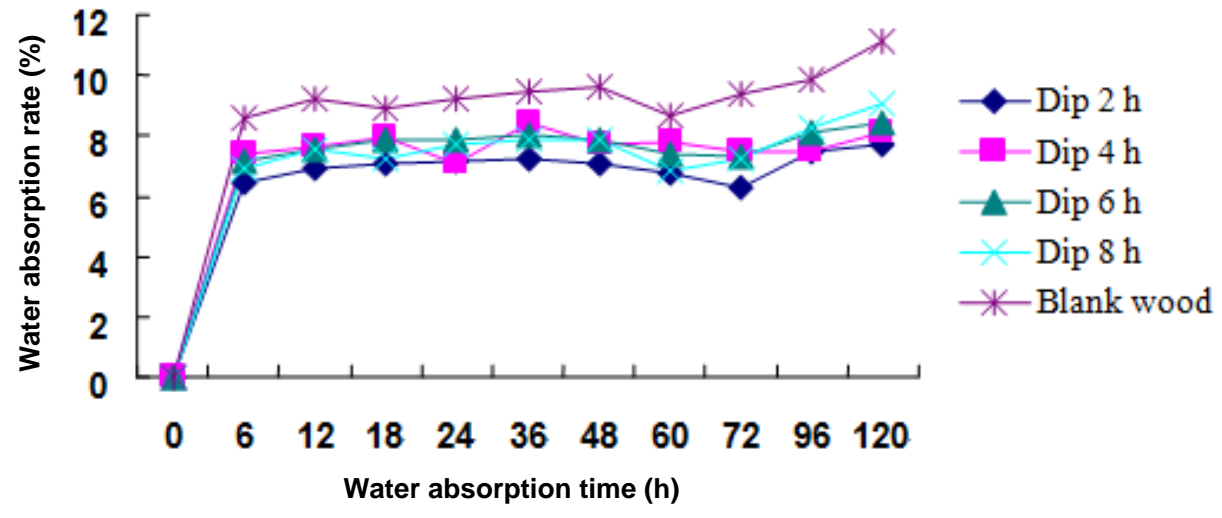

Fig. 10. Water absorption rates of the wood with different penetration times at different water absorption times 
The water absorption rates increased with the water absorption time extended to 12 $\mathrm{h}$; after $12 \mathrm{~h}$, the water absorption rates increased much more slowly, and the modified wood showed noticeably lower water absorption rates than those of the unmodified wood. During penetration, the formation of $\mathrm{SiO}_{2}-\mathrm{TiO}_{2}$ occurred in situ, partially filling the pores with the mixed oxide. This would slow down the flow of water into the wood. In addition, there is evidence that hydrophobic materials from the wood were able to coat the outer surfaces after treatment.

The thickness swelling of the wood with different penetration times at different water absorption times is depicted in Fig. 11. With increasing water absorption time, the tangential and radial thickness swelling of the wood samples first increased and then gradually reached a plateau. This behavior was attributable to the considerably strong water absorption of oven-dried wood. At the beginning of water absorption the $\mathrm{SiO}_{2}$ and $\mathrm{TiO}_{2}$ particles that were formed in situ filled the major channels of water transport in the wood and bonded with hydroxyl groups on the wood surface. This bond hindered water absorption by the hydroxyl groups and reduced the moisture absorption expansion rates of the modified wood. When the moisture content of the wood reached equilibrium, the moisture absorption expansion rates stabilized. Compared with unmodified wood, the modified wood exhibited noticeably less thickness swelling, and thickness swelling in both tangential and radial sections was reduced with extended penetration time. This result suggested that modification substantially improved the dimensional stability of the wood.
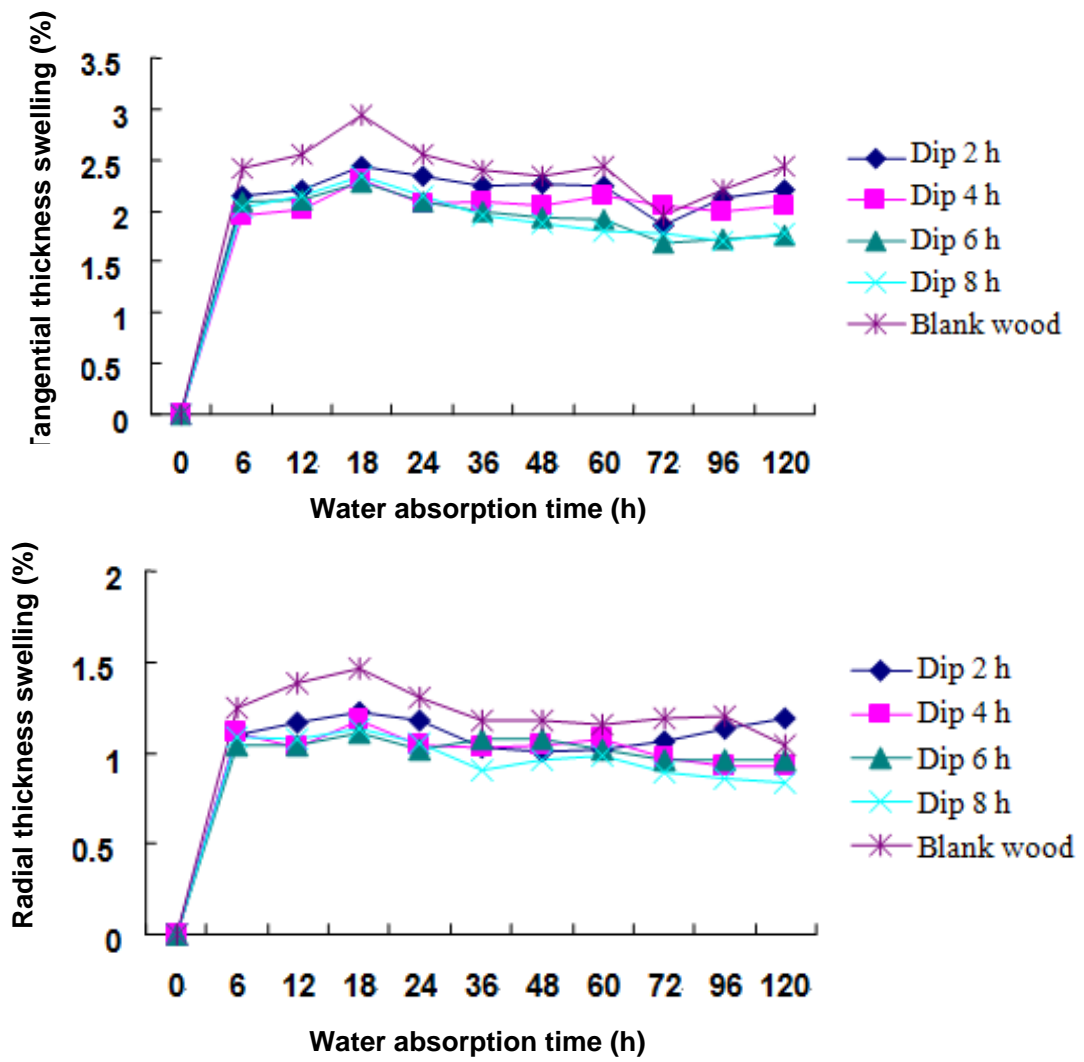

Fig. 11. Thickness swelling of wood with different penetration times at different water absorption time 


\section{CONCLUSIONS}

1. Large amounts of $\mathrm{SiO}_{2}$ and $\mathrm{TiO}_{2}$ particles were successfully formed in the cell wall and cell lumen of wood using the sol-gel method. Longer penetration time resulted in higher gel content. Modification did not alter the intrinsic structure of the wood. However, chemical bonds were formed between $\mathrm{SiO}_{2} / \mathrm{TiO}_{2}$ and wood.

2. Modified wood exhibited a higher photocatalytic activity, compared with unmodified wood. The concentration of the azo dye gradually decreased during photocatalysis, and the speed of degradation was higher for the wood samples modified with longer penetration time.

3. Modification noticeably increased the hydrophobicity of the wood but exerted no evident effects on wood durability.

4. Modified wood showed noticeably improved aging resistance, which was more than four-fold that of unmodified wood. Compared with unmodified wood, modified wood exhibited lower water absorption, less thickness swelling, and noticeably improved dimensional stability.

\section{REFERENCES CITED}

Chang, F., Jiao, M., Xu, Q., Deng, B., and Hu, X. (2018). "Facile fabrication of mesoporous Fe-Ti-SBA15 silica with enhanced visible-light-driven simultaneous photocatalytic degradation and reduction reactions," Applied Surface Science 435, 708-717. DOI: 10.1016/j.apsusc.2017.11.168

Dong, Y., Yuan, B., and Ji, X. (2017). "Preparation of wood-basedg- $\mathrm{C}_{3} \mathrm{~N}_{4} / \mathrm{TiO}_{2}$ composite coating and characterization of its photocatalytic properties," Journal of Beijing Forestry University 39(12), 112-117. DOI: 10.13332/j.1000-1522.20170266

Guo, T. (2017). Research on Performance and Preparation of Wooden Integrate Absorbing and Reflection Mechanism Electromagnetic Shielding Materials, MS Thesis, Mongolia Agricultural University, Hohhot, China.

Guo, D., Xiao, J., Chen, J., Liu, Y., Yu, C., Cao, M., and Jiang, L. (2015). "Superhydrophobic "Aspirator": Toward dispersion and manipulation of micro/nanoliter droplets," Small 11(35), 4491-4496. DOI: 10.1002/smll.201501023

Guo, H., Fuchs, P., Cabane, E., Michen, B., Hagendorfer, H., and Romanyuk, Y. E. (2016). "UV-protection of wood surfaces by controlled morphology fine-tuning of ZnO nano structures," Holzforschung 70(8), 699-708. DOI: 10.1515/hf-2015-0185

Huang, Y., Hu, Y., Zhu, C., Zhang, F., Li, H., Lu, X., and Meng, S. (2016). "Long-lived multifunctional superhydrophobic heterostructure via molecular self-supply," Advanced Materials Interfaces 3(5), Article ID 1500727. DOI: 10.1002/admi.201500727

Jiang, Z., Sun, F., and Yu, Y. (2010). "Modification of nano $\mathrm{TiO}_{2}$ on bamboo and its antiphoto discoloration performance," Scientia Silvae Sinicae 46(2), 116-121. DOI: 10.3724/SP.J.1238.2010.00474

Jin, C., Li, J., Han, S., Wang, J., Yao, Q., and Sun, Q. (2015). "Silver mirror reaction as an approach to construct a durable, robust super hydrophobic surface of bamboo 
timber with high conductivity," Journal of Alloys and Compounds 635, 300-306. DOI: 10.1016/j.jallcom.2015.02.047

Jin, C., Yao, Q., Li, J., Fan, B., and Sun, Q. (2015). "Fabrication, super hydrophobicity, and microwave absorbing properties of the magnetic $\gamma-\mathrm{Fe}_{2} \mathrm{O}_{3}$ /bamboo composites," Materials \& Design 85, 205-210. DOI: 10.1016/j.matdes.2015.07.016

Liao, Q., Lu, C., and Xu, C. (2001). "Preparation of wood-PMMA-SiO2 composites by sol-gel and its microstructure," Chemical Engineering \& Equipment (1), 21-23.

Li, J., Sun, Q., Han, S., Wang, J., Wang, Z., and Jin, C. (2015). "Reversibly lightswitchable wettability between superhydrophobicity and superhydrophilicity of hybrid $\mathrm{ZnO}$ /bamboo surfaces via alternation of UV irradiation and dark storage," Progress in Organic Coatings 87, 155-160. DOI: 10.1016/j.porgcoat.2015.05.028

Lin, L., Wang, H., Luo, H., and Xu, P. (2015). "Enhanced photocatalysis using sideglowing optical fibers coated with $\mathrm{Fe}$-doped $\mathrm{TiO}_{2}$ nano composite thin films," Journal of Photochemistry \& Photobiology A: Chemistry 307-308, 88-98. DOI: 10.1016/j.jphotochem.2015.04.010

Liu, F., Wang, S., Zhang, M., Ma, M., Wang, C., and Li, J. (2013). "Improvement of mechanical robustness of the superhydrophobic wood surface by coating $\mathrm{PVA} / \mathrm{SiO}_{2}$ composite polymer," Applied Surface Science 280, 686-692. DOI: 10.1016/j.apsusc.2013.05.043

Li, R., Xu, W., Wang, X., and Wang, C. (2018). "Modeling and predicting of the color changes of wood surface during $\mathrm{CO}_{2}$ laser modification," Journal of Cleaner Production 183, 818-823. DOI: 10.1016/j.jclepro.201802194

Lou, Z., Sun, J., Lu, H., Cai, J., Xou, J., Li, X., Sun, Z., and He, H. (2017). "Fabrication of magnetic wood and its magnetic and electromagnetic wave absorption properties," Journal of Forestry Engineering 2(4), 24-29. DOI: 10.13360/j.issn.20961359.2017.04.004

Miyafuji, H., Saka S., and Yamamoto, A. (1998). " $\mathrm{SiO}_{2}-\mathrm{P}_{2} \mathrm{O}_{5}-\mathrm{B}_{2} \mathrm{O}_{3}$ wood-inorganic composite prepared by metal alkoxide oligomers and their fire-resisting properties," Holzforschung 52(4), 410-416. DOI: 10.1515/hfsg.1998.52.4.410

Mo, Y., Chen, K., He, Q., and Fu, Y. (2012). "Modifying wood surface properties by $\mathrm{SiO}_{2}$ polyurethane coating," Journal of Beijing Forestry University 34(4), 154-159. DOI: $10.1007 / \mathrm{s} 11783-011-0280-\mathrm{z}$

Mo, Y., and Fu, Y. (2009). "The application of nano $\mathrm{SiO}_{2}$ in coatings," Paint \& Coatings Industry 39(11), 63-66. DOI: 10.3969/j.issn.0253-4312.2009.11.017

Muff, L. F., Luxbacher, T., Burgert, I., and Michen, B. (2018). "Investigating the timedependent zeta potential of wood surfaces," Journal of Colloid and Interface Science 518, 165-173. DOI: 10.1016/j.jcis.2018.02.022

Ogiso, K., and Saka, S. (1994). "Wood-inorganic composite prepared by sol-gel process IV. Effects of chemical bonds between wood and inorganic substances on property enhancement," Mokuzai Gakkaishi 40(10), 1100-1106

Pan, Y., Huang, J., Guo, T., and Zhang, S. (2015). "Nano-SiC effect on wood electroless Ni-P composite coatings," Proceedings of the Institution of Mechanical Engineers, Part N: Journal of Nanoengineering and Nanosystems 229(4), 154-159. DOI: 10.1177/1740349914530683

Qiu, J., and Li, J. (2005). "Preparation of wood-silica aerogels composites by supercritical drying technique and its nano-structure," Journal of Northeast Forestry University 33(3), 3-4. 
Rao, X., Liu, Y., Fu, Y., Liu, Y., and Yu, H. (2016). "Formation and properties of polyelectrolytes/ $/ \mathrm{TiO}_{2}$ composite coating on wood surfaces through layer-by-layer assembly method," Holzforschung 70(4), 361-367. DOI: 10.1515/hf-2015-0047

Saka, S., Megumi, S., and Mitsuhiko, T. (1992). "Wood-inorganic composite prepared by sol-gel processing I. Wood-inorganic composite with porous structure," Mokuzai Gakkaishi 38(11), 1043-1049.

Sun, L., Mo, X., Cheng, Z., Tian, J., and Wang, X. (1998). "Preparation of wood/silica nanocomposite by chemical methods," China Building Materials Science \& Technology 7(3), 23-28.

Sun, F., Wu, M., and Li, W. (1995). "The relationship between size and photocatalytic activity of $\mathrm{TiO}_{2}$," Chinese Journal of Catalysis 19, 229-233.

Wang, K., Chen, Y., and Ye, F. (2004). "Degradation of dye pollutants on $\mathrm{SiO}_{2}-$ supported $\mathrm{TiO}_{2}$ photocatalyst under visible light irradiation," Chinese Journal of Catalysis 25(12), 931-936. DOI: 10.2174/0929866043478455

$\mathrm{Wu}, \mathrm{T}$., and Zhang, W. (2011). "The preparation of nano $\mathrm{TiO}_{2} /$ poplar composites," Science \& Technology Association Forum 8, 92-94. DOI: 10.3969/j.issn.10073973.2011.08.055

Ye, Y., and Li, Q. (2012). "Preparation of mesoporous titanium dioxide and research," Analytical Instrumentation (6), 68-76.

Zhang, L., Tang, B., Wu, J., Li, R., and Wang, P. (2015). "Hydrophobic light-to-heat conversion membranes with self-healing ability for interfacial solar heating," Advanced Materials 27(33), 4889-4894. DOI: 10.1002/adma.201502362

Zhang, Y., Yang, X., and Xiao, C. (2012). "Construction of flower-like $\mathrm{TiO}_{2}$ on the wood surface and research of woods hydrophobicity," Yunnan Chemical Technology 39(2), 1-3. DOI: 10.3969/j.issn.1004-275X.2012.02.001

Zhong, S., Li, C., Sun, H., and Xiao, X. (2002). "Preparation and characterization supported $\mathrm{TiO}_{2}$-polypropylene hydrophobic composite membranes," Membrane Science and Technology 22(4), 21-25. DOI: 10.3969/j.issn.1007-8924.2002.04.004

Article submitted: January 1, 2020; Peer review completed: October 4, 2020; Revised version received and accepted: November 23, 2020; Published: December 8, 2020. DOI: 10.15376/biores.16.1.747-763 